\title{
Gerenciamento de Resultados em Bancos com Uso de TVM: Validação de Modelo de Dois Estágios
}

\section{Securities-Based Earnings Management in Banks: Validation of a Two-Stage Model}

\author{
José Alves Dantas \\ Professor Doutor do Departamento de Ciências Contábeis do Centro Universitário de Brasília \\ E-mail: josealvesdantas@gmail.com \\ Otávio Ribeiro de Medeiros \\ Professor Titular do Departamento de Ciências Contábeis e Atuariais da Universidade de Brasília \\ E-mail: otavio@unb.br \\ Fernando Caio Galdi \\ Professor Associado do Departamento de Contabilidade e Finanças da FUCAPE Business School \\ E-mail: Fernando.galdi@fucape.br
}

Fábio Moraes da Costa

Professor Associado do Departamento de Contabilidade e Finanças da FUCAPE Business School

E-mail: fabio@fucape.br

Recebido em 2.11.2011 - Aceito em 3.11.2011 - 3 ${ }^{a}$. versão aceita em 21.6.2012

\section{RESUMO}

Estudos sobre gerenciamento de resultados em bancos têm se preocupado especialmente com o uso da provisão para créditos de liquidação duvidosa (PCLD) e utilizam principalmente modelos de dois estágios para a identificação da ação discricionária da administração. Outro tipo de registro que tem recebido atenção dos pesquisadores na identificação dessa prática em bancos é a classificação e a mensuração do valor justo dos títulos e valores mobiliários (TVM). Nesse caso, porém, têm prevalecido modelos de um estágio. Este estudo tem por objetivo desenvolver e validar um modelo de dois estágios para a identificação da discricionariedade nos resultados com TVM. O modelo incorpora preceitos dos poucos estudos sobre o tema, parâmetros utilizados nos modelos para identificação da PCLD discricionária em bancos, além de indicadores macroeconômicos e características específicas de composição da carteira de TVM. Os testes empíricos tiveram por base as informações dos bancos comerciais, bancos múltiplos e caixas econômicas em atuação no mercado brasileiro, entre o terceiro trimestre de 2002 e o quarto trimestre de 2010. Para a validação do modelo proposto, os seus resultados foram cotejados com os decorrentes da aplicação de um modelo de um estágio metodologia difundida na literatura sobre o tema. Os testes realizados com os dois modelos revelam evidências da prática de alisamento de resultados com o uso de TVM, bem como a utilização da classificação em títulos disponíveis para venda nessas ações de gerenciamento. A consistência dos resultados encontrados nos dois modelos evidencia a validação do modelo proposto, contribuindo para o desenvolvimento de pesquisas sobre o tema que se preocupem não apenas em constatar se há a prática ou não do gerenciamento, mas também associá-la a outras variáveis. Neste estudo, por exemplo, foi constatado que essa prática é mais relevante nos bancos de menor porte e nos controlados por capital privado.

Palavras-chave: Alisamento de resultados. TVM. Discricionário. Bancos. Manipulação.

\section{ABSTRACT}

Studies investigating earnings management in banks have been particularly concerned with the use of Loan Loss Provisions (LLP) and mainly use two-stage models to identify discretionary management actions. Another type of record that has received attention from researchers in identifying discretionary management actions is the classification and measurement of the fair value of securities. In this case, however, one-stage models have prevailed. The present study aims to develop and validate a two-stage model for the identification of discretionary management actions using gains obtained from securities. Our model incorporates macroeconomic indicators and specific attributes of the securities portfolios to the traditional parameters used in models previously utilized in the literature. To validate the proposed model, the results are compared with the results from the estimation of a one-stage model-a methodology widely used in the literature. Tests conducted with the two models reveal evidence of income smoothing using securities and the classification of available-for-sale securities among the actions taken by management. The consistency of the results across the two models validates the proposed model, thereby contributing to the development of research on the topic that is not only concerned with determining whether earnings management is practiced but also whether it can be associated with other variables. We also find that securities-based earnings management is more significant in smaller-sized banks and in banks controlled by private capital.

Keywords: Earnings management. Securities. Discretionary. Banks. Manipulation. 


\section{INTRODUÇÃO}

Estudos empíricos sobre escolhas contábeis, manipulação das informações contábeis e gerenciamento de resultados representam uma das áreas que mais tem recebido atenção dos pesquisadores, avaliando-se a utilização das informações financeiras no âmbito do mercado de capitais (Kothari, 2001; Fields, Lys, \& Vincent, 2001).

Quanto aos procedimentos metodológicos utilizados para a identificação do earnings management, embora alguns estudos utilizem a distribuição de frequências (histogramas), o que tem prevalecido na literatura empírica sobre gerenciamento de resultados é a análise do comportamento dos accruals, em particular a parcela relacionada à ação discricionária da administração (Healy \& Wahlen, 1999). Para mensurar essa discricionariedade, várias construções econométricas foram desenvolvidas, destacando-se, de acordo com Paulo (2007), os modelos de: Healy (1985); DeAngelo (1986); Jones (1991); Dechow, Sloan e Sweeney (1995), denominado de Jones Modificado, por ser um desdobramento daquele; e Kang e Sivaramakrishnan (1995), o KS. De forma geral, esses modelos procuram segregar a parcela das acumulações agregadas (accruals totais) que são determinadas pela discricionariedade dos gestores, em resposta aos seus incentivos, e se propõem a ser aplicáveis aos diversos segmentos econômicos.

Não obstante o número de estudos sobre o tema utilizando esses modelos, algumas limitações metodológicas são salientadas na literatura, entre as quais: a dificuldade de detectar e medir a prática do gerenciamento de resultados (Dechow, Sloan, \& Sweeney, 1995); a limitação dos modelos econométricos para capturar a discricionariedade da administração no reconhecimento dos accruals (Paulo, 2007; Jones, Krishnan, \& Melendrez, 2008); e o fato de os accruals anormais, utilizados como parâmetro de discricionariedade e proxy para o gerenciamento de resultados, serem influenciados por fatores não discricionários não usuais (Healy, 1996; Bernard \& Skinner, 1996).

Até como forma de se lidar com as limitações dos modelos econométricos, outra dimensão dos estudos sobre gerenciamento de resultados se concentra na análise das acumulações específicas. Conforme Martinez (2001) e Cheng, Warfield e Ye (2011), o foco na análise de contas específicas (ou de uma indústria) proporciona a oportunidade de uma modelagem mais compatível e adequada ao problema apreciado. A utilização desse método, que produz evidências empíricas a respeito das contas usadas para o gerenciamento, também é destacada por Healy e Wahlen (1999) e McNichols (2000) como a forma de maior potencial de progresso para a literatura sobre o tema.

Por suas características particulares, a indústria bancária tem sido um ambiente propício ao desenvolvimento de estudos baseados em accruals específicos. Para Kanagaretnam, Krishnan e Lobo (2010), a utilização de accrual específico em uma indústria como a bancária possibilita uma segregação mais apropriada dos componentes discricionários e não discricionários, além de permitir o controle de outros determinantes de diferenças cross-sectional nos accruals, aumen- tando a confiabilidade das inferências das análises empíricas. Esses estudos se concentram especialmente na análise do processo de constituição das provisões para créditos de liquidação duvidosa (PCLD), o que é justificado por Kanagaretnam, Lobo e Mathieu (2003) com o argumento de que essas provisões representam, de modo geral, os maiores accruals dos bancos, desempenhando papel fundamental nas decisões dos gestores sobre eventuais manipulações contábeis. Segundo Alali e Jaggi (2010), há uma crença generalizada no mercado de que os administradores dos bancos usam extensivamente a PCLD para manipular os resultados divulgados, o que tem sido foco de preocupação dos reguladores.

Além da PCLD, outro tipo de registro constantemente estudado para a identificação da prática de gerenciamento de resultados em instituições financeiras é a classificação e a mensuração do valor justo dos títulos e valores mobiliários (TVM), bem como a definição dos momentos de venda, o que afeta os ganhos e perdas associados a esses ativos. Segundo Beatty, Ke e Petroni (2002), os pesquisadores têm demonstrado que esses são os dois componentes de resultado dos bancos mais sujeitos à manipulação.

Entre as pesquisas realizadas na indústria bancária que se concentram na análise da PCLD ou da carteira de TVM, uma diferença se destaca. Quando o foco é a PCLD, grande parte dos estudos utiliza modelos em dois estágios - no primeiro identifica a parcela discricionária, representada pelo termo de erro do modelo de especificação da parte não discricionária, e no segundo avalia a associação entre essa discricionariedade e variáveis representativas de interesse da administração. No caso dos estudos sobre TVM, comumente são utilizados modelos de um estágio, ou seja, não são identificadas as parcelas resultantes da ação discricionária da administração - geralmente é avaliada a associação entre os accruals totais com TVM e variáveis de resultados eliminando-se essas acumulações, para concluir se a instituição financeira utiliza as acumulações com TVM para alcançar os resultados de interesse dos gestores. A utilização de modelos de um estágio pode ter como consequência a dificuldade de desenvolvimento de pesquisas em que seja necessária a informação sobre a dimensão da discricionariedade praticada pelas instituições, em cada momento. Adicionalmente, é importante considerar que no processo de mensuração dos instrumentos financeiros há duas parcelas. A primeira diz respeito ao reconhecimento dos juros do período (nos casos em que seja necessário), existindo poucas oportunidades para o gestor exercer discricionariedade para a manipulação do resultado. A segunda parcela diz respeito à atualização do valor justo do instrumento, ocasião em que o gestor pode atuar mais discricionariamente no sentido de manipular o resultado de uma instituição. Assim, é recomendável que a avaliação empírica de gerenciamento de resultados com TVM considere a separação das parcelas discricionária e não discricionária.

Considerando esse contexto, é formulado o problema de pesquisa que o presente estudo pretende responder: "a utilização de modelo de dois estágios para a identificação da ação discricionária dos administradores das instituições fi- 
nanceiras na avaliação dos títulos e valores mobiliários oferece resultados compatíveis com os modelos de um estágio - mais comumente utilizados em pesquisas sobre o tema?"

Assim, coerente com esse problema, o estudo tem por objetivo validar um modelo de dois estágios para a identificação da discricionariedade das acumulações com TVM, por parte de instituições financeiras, buscando aprimorar os poucos modelos com essas características identificados na literatura. Para esse fim, são consideradas as poucas contribuições dos estudos sobre o tema na área bancária, incorporando os preceitos adotados no desenvolvimento dos modelos de dois estágios para PCLD e as características das carteiras de títulos e valores mobiliários. A validação do modelo proposto se dará pelo cotejamento dos resultados apurados com os encontrados com a utilização de um modelo de um estágio, dada a consolidação na literatura desse tipo de modelo para o gerenciamento de resultados em bancos com o uso de TVM. Esse procedimento de validação procura se prevenir em relação ao problema destacado por Lobo e Yang (2001), que atribui a existência de resultados empíricos conflitantes nos estudos sobre gerenciamento de resultados à utilização de diferentes modelos e à ausência de consenso metodológico entre os pesquisadores.

Para a realização dos testes empíricos são utilizados os dados das Informações Financeiras Trimestrais (IFT) dos bancos comerciais, bancos múltiplos e caixas econômicas em atuação no mercado brasileiro, entre o terceiro trimestre de 2002 e o quarto trimestre de 2010, disponíveis na página do Banco Central do Brasil (BCB) na internet.

Não obstante a preocupação externada por Goldberger (1961) quanto à subestimação do valor absoluto dos coeficientes da regressão no segundo estágio, a validação de um modelo de dois estágios para identificar a discricionariedade na avaliação e classificação da carteira de títulos e valores mobiliários contribui para o desenvolvimento de pesquisas sobre o tema que se preocupem não apenas em concluir se há ou não a prática do gerenciamento de resultados, mas também identificar qual a dimensão da discricionariedade praticada. Além do mais, pode servir como subsídio para o desenvolvimento de estudos em que a discricionariedade da administração da instituição bancária em relação à carteira de TVM seja um dos elementos a se considerar.

\section{REFERENCIAL TEÓRICO}

Como suporte teórico para o desenvolvimento do modelo, são discutidos os seguintes temas: a prática do gerenciamento de resultados em instituições financeiras; o uso da carteira de TVM para essa prática; uma revisão de pesquisas sobre o uso de TVM pelos bancos para a prática do gerenciamento; e a utilização de modelos de dois estágios para a identificação da ação discricionária dos gestores das instituições bancárias.

\subsection{Prática do Gerenciamento de Resultados em Instituições Financeiras.}

Segundo Cornett, McNutt e Tehranian (2006), o estudo do gerenciamento de resultados no sistema financeiro é particularmente crítico, tendo em vista os impactos que problemas em instituições bancárias podem provocar na economia. Esse entendimento é reforçado pelo cenário da crise financeira de 2008, quando bancos importantes, considerados grandes demais para quebrar - too big to fail - foram socorridos por governos nacionais, em momento de desconfiança generalizada, para evitar consequências ainda mais devastadoras para os sistemas financeiros e a economia global. Aliás, de acordo com Cheng, Warfield e Ye (2011), os efeitos dessa crise aumentam a relevância de se investigar a prática do gerenciamento de resultados na indústria bancária, tendo em vista a criticidade dos bancos na composição da economia.

Goulart (2007) também afirma que uma das bases de um sistema financeiro sólido é a transparência, razão pela qual órgãos internacionais e bancos centrais de diversas nações defendem a divulgação, pelas instituições financeiras, de informações que evidenciem adequadamente a sua situação patrimonial, financeira e de resultados, além de outros aspectos como a estrutura organizacional, controles internos e gestão de riscos. O pressuposto é que esse re- quisito de transparência seja suprido, principalmente, pelas demonstrações financeiras. As práticas de gerenciamento de resultados, no entanto, podem representar um comprometimento da divulgação da efetiva situação dessas entidades, segundo o autor.

Além das preocupações com a eventual manipulação para encobrir uma situação que possa comprometer a saúde financeira da instituição e com a necessidade de redução da assimetria de informações entre os acionistas da instituição, a questão do gerenciamento de resultados em instituições bancárias envolve outro aspecto relevante, destacado por Marcondes (2008), que é o seu impacto na disciplina de mercado. $\mathrm{O}$ autor constatou empiricamente que a manipulação contábil, medida pelas acumulações discricionárias, tem influência na redução das taxas de juros negociadas entre os bancos e os depositantes, gerando benefícios para as instituições financeiras que utilizam essa prática - pagam aos depositantes taxas de juros menores do que os indicadores de risco sugeririam sem essas acumulações, configurando a transferência de renda entre esses agentes.

\subsection{O Uso da Carteira de TVM para} Gerenciamento de Resultados em Bancos.

Conforme destacado na parte introdutória, os estudos sobre gerenciamento de resultados em instituições financeiras se concentram em modelos de accruals específicos, focando, em particular, na análise do comportamento das provisões para créditos de liquidação duvidosa. Outra área que merece preocupação em relação à possibilidade de manipulação da informação financeira das instituições bancárias é a classificação e a mensuração do valor justo dos títulos e valores mobiliários. De acordo com Beatty, Ke e Petroni (2002), esses são os dois componentes de resultado dos bancos mais sujeitos à manipulação, conforme demonstrado pelos pesquisadores. 
Em relação à classificação dos TVM, a possibilidade de gerenciamento reside nos efeitos nos resultados da instituição decorrentes da escolha da categoria em que é reconhecido, de acordo com os critérios definidos pelo BCB, através da Circular 3.068, de 08/11/2001, sintetizados na Tabela 1. Como os parâmetros de avaliação e o impacto no resultado são diferenciados em função da categoria em que o TVM é classificado, a administração pode utilizar essa prerrogativa para praticar o earnings management. Cabe ressaltar que as recentes alterações introduzidas por meio da International Financial Reporting Standard - IFRS 9, com previsão de vigência a partir de $1^{\circ}$. de janeiro de 2015, modifica essa classificação e os critérios de avaliação e reconhecimento, mas os seus preceitos não são considerados neste estudo, tendo em vista que: ainda não foram recepcionados pelo arcabouço normativo definido pelo $\mathrm{BCB}$ e, mesmo que fosse o caso, o seu prazo de vigência não alcançaria a abrangência da pesquisa.

Tabela 1

Categorias e parâmetros de avaliação de TVM

\begin{tabular}{l|l|l}
\hline Categoria de classificação & Critério de avaliação & Reconhecimento dos efeitos \\
\hline Títulos para negociação & Valor justo & No resultado do período \\
\hline Títulos disponíveis para venda & Valor justo & No Patrimônio Líquido \\
\hline Títulos mantidos até o vencimento & Custo amortizado & No resultado do período \\
\hline
\end{tabular}

Fonte: Circular BCB 3.068/2001.

No tocante à mensuração do valor justo, Fiechter e Meyer (2010) destacam que o processo de avaliação dos instrumentos financeiros a fair value, em particular quando são ou tornam-se ilíquidos, é complexo, baseado em condições subjetivas e de difícil verificação, envolvendo margem considerável de incerteza. Em tais situações, se requer a utilização de modelos de precificação, com as dificuldades inerentes à definição de premissas (Goulart, 2007). Isso contribui para um ambiente propício ao gerenciamento das informações financeiras por parte da administração, não obstante os requerimentos abrangentes de disclosure (Fiechter \& Meyer, 2010). Nissim (2003) também ressalta que, embora of fair value esteja sendo crescentemente recomendado por reguladores e demandado por usuários das demonstrações financeiras como base de mensuração contábil, persistem críticas quanto a potencial incerteza quando não há preço de mercado para o ativo.

$\mathrm{Na}$ crise financeira de 2008, por exemplo, o ambiente de instabilidade levou a International Federation of Accountants (IFAC, 2008) a divulgar um alerta para auxiliar os auditores na verificação do valor justo de instrumentos financeiros, no qual é destacada a preocupação com o grau de incerteza, na ausência de um valor de mercado ativo. Segundo a IFAC, isso cria um ambiente de tentação natural para o viés no julgamento da administração, evidenciando um cenário mais favorável que o efetivo, devendo o auditor identificar indicadores de possível viés da administração.

\subsection{Pesquisas sobre o Uso de TVM para Gerenciamento de Resultados em Bancos.}

O uso da carteira de títulos e valores mobiliários para o gerenciamento de resultados ou de capital por parte das instituições bancárias tem merecido atenção de pesquisadores contábeis, principalmente quanto à prática do alisamento de resultados, tanto no cenário internacional quanto no mercado brasileiro.

Em âmbito internacional podem ser destacados, entre outros, os seguintes estudos e evidências: Moyer (1990) não encontrou evidências de uso de ganhos e perdas com TVM para gerenciamento de capital; Beatty, Chamberlain e Ma- gliolo (1995) e Kanagaretnam, Lobo e Mathieu (2003, 2004) constataram o uso das operações com TVM, geralmente de forma conjunta e complementar com a constituição da PCLD, para o gerenciamento de resultados, em particular o income smoothing; Beatty e Harris (1999), Beatty, Ke e Petroni (2002) e Shrieves e Dahl (2003) confirmaram que os bancos de capital aberto se envolvem mais na prática do earnings management, utilizando os ganhos e perdas com títulos, do que os de capital fechado; Fiechter e Meyer (2010) identificaram que os bancos usaram a discricionariedade dos instrumentos financeiros nível 3 - os que apresentam maior grau de subjetividade, dada a ausência de mercados ativos - durante a crise financeira de 2008, com o propósito de praticar o big bath accounting (caracterizado pela antecipação de despesas que não precisariam ser reconhecidas no exercício corrente, criando condições para aumento dos resultados futuros); Quagli e Ricciardi (2010) verificaram que bancos europeus utilizaram as novas possibilidades de reclassificação dos instrumentos financeiros, permitidas pelo amendment de $\mathrm{Ou}-$ tubro de 2008 à International Accounting Standard - IAS 39, para a prática do gerenciamento de resultados, mas não do nível de capitalização.

No mercado brasileiro, Zenderski (2005), Monteiro e Grateron (2006), Santos (2007), Xavier (2007), Goulart (2007), Baggio, Monteiro e Toda (2007) e Gabriel e Corrar (2010) também avaliaram a utilização da discricionariedade em relação à classificação e mensuração a valor justo da carteira de TVM para fins de gerenciamento de resultados ou de capital.

Evidências da prática do income smoothing por parte das instituições bancárias brasileiras, com o uso da discricionariedade na constituição da PCLD e nos ajustes a valor de mercado dos TVM, de forma conjunta e complementar, foram encontradas por Zenderski (2005) e Santos (2007). Goulart (2007) também encontrou evidências de gerenciamento de resultados com o uso da PCLD, avaliação de títulos e valores mobiliários e resultados com derivativos, com a ressalva de que a expectativa do income smoothing com o uso de operações com TVM só foi confirmada nos casos de ajustes positivos no valor dos títulos. 
A análise do impacto da adoção do fair value para a mensuração dos títulos e valores mobiliários, em junho de 2002, foi realizada por Monteiro e Grateron (2006), concluindo-se que houve uma redução da volatilidade, exibindo evidências de alisamento de resultados por parte das instituições bancárias analisadas, com o uso dos ajustes a valor justo dos TVM. Em estudo posterior, utilizando dados semestrais de 2002 a 2005, Baggio, Monteiro e Toda (2007) constataram que a volatilidade do capital próprio dos bancos vem aumentando desde a adoção do critério de fair value para a mensuração dos instrumentos financeiros.

A hipótese de gerenciamento de resultados, usando os ágios em investimentos em controladas e coligadas, as operações com títulos e valores mobiliários, as provisões para operações de crédito ou os passivos contingentes, foi analisada por Xavier (2007), que constatou que 55\% dos bancos examinados utilizaram a classificação dos TVM para a prática do earnings management.

Gabriel e Corrar (2010) adotam um modelo de dois estágios para a identificação das parcelas discricionária e não discricionária do ajuste a fair value da carteira de TVM, para verificar se os bancos brasileiros usam as prerrogativas de mensuração dos títulos e valores mobiliários para gerenciar resultados e capital, concluindo que os gestores das instituições financeiras utilizam o ajuste ao valor de mercado como meio de gerenciamento de resultados e, de forma complementar, como gerenciamento do nível de capital próprio. Como ressalva, há de se destacar que no segundo estágio foi encontrada relação positiva entre a parcela discricionária do ajuste a valor de mercado e o resultado do trimestre, contrariando as evidências de income smoothing no mercado brasileiro, encontradas por Zenderski (2005), Monteiro e Grateron (2006), Santos (2007) e Goulart (2007).

\subsection{Uso de Modelos de Dois Estágios para a Identificação do Gerenciamento com TVM.}

$\mathrm{Na}$ análise de acumulações específicas, como é o caso dos ganhos e perdas com TVM, para o gerenciamento de resultados, podem ser adotados como procedimentos de pesquisa, segundo Goulart (2007): (i) a estimação e análise da relação com o resultado contábil, aqui denominado como modelo de um estágio, com o fim de identificar possível uso na suavização de resultados; e (ii) a utilização de modelo para estimar o componente discricionário da conta específica sob análise, conhecido como modelo de dois estágios. A diferença entre os dois procedimentos, portanto, é que, no modelo de dois estágios, primeiro se identifica a parcela discricionária da variável dependente, representada pelo termo de erro do modelo de especificação da parte não discricionária e, no segundo momento, se avalia a relação entre essa parcela discricionária e variáveis representativas de interesse da administração. No modelo de um estágio, não há a segregação da parcela discricionária.

$\mathrm{Na}$ literatura sobre o uso dos resultados com TVM para fins de gerenciamento de resultados ou de nível de capital em instituições financeiras tem prevalecido o primeiro método, conhecido como modelo de um estágio. Nos estudos listados na seção anterior, por exemplo, apenas quatro - Beatty e Harris (1999), Beatty, Ke e Petroni (2002), Fiechter e Meyer (2010) e Gabriel e Corrar (2010) - trabalharam com modelos de dois estágios, em que no primeiro momento se identifica a parcela discricionária, representada pelo termo de erro do modelo de especificação da parte não discricionária, e no segundo se avalia a associação entre essa discricionariedade e as variáveis de interesse do estudo.

A síntese dos modelos utilizados para especificação da parcela não discricionária dos resultados com TVM são destacadas na Tabela 2.

Tabela 2 Síntese dos modelos de especificação da parcela não discricionária dos resultados com TVM em bancos

\begin{tabular}{|c|c|c|}
\hline Estudo & Variável dependente & Variáveis independentes \\
\hline $\begin{array}{l}\text { Beatty e Harris } \\
\text { (1999) }\end{array}$ & Ganhos realizados com TVM & $\begin{array}{l}\text { Ativos totais (log natural); resultado positivo antes dos tributos e do resultado } \\
\text { realizado com TVM (dummy); banco com capital aberto (dummy); capital } \\
\text { (tier 1) sem o resultado realizado com TVM; resultado não realizado com } \\
\text { TVM; e período (controle). }\end{array}$ \\
\hline $\begin{array}{l}\text { Beatty, Ke e } \\
\text { Petroni (2002) }\end{array}$ & $\begin{array}{l}\text { Ganhos e perdas realizados } \\
\text { com TVM }\end{array}$ & Ativos totais (log natural); e ganhos e perdas não realizados com TVM em t-1. \\
\hline $\begin{array}{l}\text { Fiechter e } \\
\text { Meyer (2010) }\end{array}$ & $\begin{array}{l}\text { Ganhos e perdas não } \\
\text { realizadas com TVM nível } 3\end{array}$ & $\begin{array}{l}\text { Posição de ativos nível } 3 \text { em t-1; relação market to book em t-1; ativos totais } \\
\text { (log natural) em t- } 1 \text {; alavancagem (dívida/ativos) em t-1; PCLD; resultado } \\
\text { não financeiro; período (controle); classificação da instituição na indústria } \\
\text { bancária (dummy). }\end{array}$ \\
\hline $\begin{array}{l}\text { Gabriel e } \\
\text { Corrar (2010) }\end{array}$ & $\begin{array}{l}\text { Ajuste ao valor de mercado } \\
\text { total dos TVM para negociação } \\
\text { e disponíveis para venda }\end{array}$ & $\begin{array}{l}\text { Variação dos TVM para negociação e disponíveis para venda; e ajuste ao } \\
\text { valor de mercado total dos TVM para negociação e disponíveis para venda } \\
\text { em t-1. }\end{array}$ \\
\hline
\end{tabular}

Procedimento comum adotado nos quatro modelos é o escalonamento das variáveis monetárias, como é o caso de todas as variáveis dependentes e de algumas independentes - capital, resultados, posição de ativos nível 3, PCLD, variação do saldo de TVM, ajustes a valor de mercado, etc. A diferença se dá em relação ao parâmetro utilizado para o escalonamento: Beatty e Harris (1999) e Gabriel e Corrar (2010) utilizaram os ativos totais; Beatty, Ke e Petroni (2002), os ativos totais no início do período; e Fiechter e
Meyer (2010), o patrimônio líquido no início do período.

Quanto à pertinência dos modelos para capturar a parcela não discricionária dos resultados com TVM, e por decorrência a discricionariedade da administração (o termo de erro), é importante ressaltar que a consideração de algumas variáveis independentes na especificação do que seria a parcela "não discricionária" dos resultados com TVM pode ser questionável. Variáveis como tamanho da instituição, resultados antes dos ganhos e perdas com 
TVM, tipo de instituição (capital aberto ou fechado), nível de capitalização, relação market to book, alavancagem, provisão para perdas com operações de crédito, por exemplo, parecem caracterizar mais apropriadamente evidências de discricionariedade da administração, que uma relação "natural" da dimensão dos resultados com TVM. É o caso, particularmente, dos modelos de Beatty e Harris (1999) e Fiechter e Meyer (2010). Embora a necessidade de se atender a interesses específicos da pesquisa possa justificar a incorporação desse tipo de variável nos modelos, para isolar do termo de erro o impacto dessas variáveis, talvez não seja muito apropriado denominá-las de parcelas discricionárias e não discricionárias.

No caso dos modelos de Beatty, Ke e Petroni (2002) e Gabriel e Corrar (2010), há de se ressaltar o pequeno nú- mero de variáveis explicativas, que seriam os determinantes da parcela não discricionária dos accruals. Uma provável consequência é a contaminação da parcela de erro, que representaria a ação discricionária da administração. Embora a limitação dos modelos econométricos em capturar a discricionariedade da administração no reconhecimento dos accruals seja uma questão abordada por diversos autores (Dechow, Sloan, \& Sweeney, 1995; Healy, 1996; Bernard \& Skinner, 1996; Paulo, 2007; Jones, Krishnan, \& Melendrez, 2008), a maior exposição ao risco de variáveis omitidas pode potencializar esse tipo de problema. Essa pode ser a razão, por exemplo, para os resultados contraditórios encontrados por Gabriel e Corrar (2010) em relação à hipótese do income smoothing no mercado brasileiro, como destacado na Seção 2.3.

\section{PROCEDIMENTOS METODOLÓGICOS}

Tendo em vista o propósito do estudo, os procedimentos metodológicos consistem na especificação de um modelo de dois estágios com o objetivo de evidenciar a discricionariedade nos resultados com TVM e, em seguida, promover um teste de validação do referido modelo, comparando seus resultados com os de um modelo de um estágio.

$\mathrm{Na}$ construção do modelo operacional proposto, é utilizada a abordagem da pesquisa analítica, que tem como foco a modelagem dos fenômenos contábeis e econômicos, com o propósito de gerar proposições empiricamente testáveis (Paulo, 2007). Segundo Demski (2005), a construção de um modelo seria exatamente um produto da pesquisa analítica, com a aplicação de um processo dedutivo lógico. Particularmente quanto à utilização de pesquisas analíticas para os propósitos de identificação da prática de gerenciamento de resultados, Ronen e Yaari (2008) destacam diversos conceitos e modelos utilizados para esse fim.

\subsection{Modelo de dois estágios para discricionariedade com TVM.}

Tendo por base preceitos de Beatty e Harris (1999), Beatty, Ke e Petroni (2002), Fiechter e Meyer (2010) e Gabriel e Corrar (2010), comentados no referencial teórico, os modelos desenvolvidos para apurar a PCLD discricionária em bancos - como em Kanagaretnam, Lobo e Mathieu (2003, 2004), Zenderski (2005), Alali e Jaggi (2010) e Kanagaretnam, Krishnan e Lobo (2010) - e as informações sobre as carteiras de TVM disponibilizadas nas Informações Financeiras Trimestrais (IFT) dos bancos brasileiros, foi desenvolvido o seguinte modelo para identificar a parcela discricionária dos resultados com TVM:

$$
\begin{aligned}
\operatorname{RTVM}_{i, t}= & \beta_{0}+\beta_{i}+\beta_{1} T V M_{i, t-1}+\beta_{2} \Delta T V M_{i, t}+ \\
& \beta_{3} S E L_{t}+\beta_{4} P I B_{t}+\beta_{5} C A M_{t}+\beta_{6} I B O V_{t}+ \\
& \psi_{1}<T I P_{i, t}>+\psi_{2}<P R Z_{i, t}>+ \\
& \psi_{3}<C O N_{i, t}>+\varepsilon_{i, t}
\end{aligned}
$$

onde:

$R T V M_{i, t}$ : resultado com títulos e valores mobiliários do banco $i$, no período $t$, escalonado pelos ativos totais do início do período $t$;
$T V M_{i, t-1}$ : saldo da carteira de títulos e valores mobiliários do banco $i$, no período $t$ - 1 , escalonado pelos ativos totais do início do período $t$ - 1 ;

$\Delta T V M_{i, t}$ : variação na carteira de títulos e valores mobiliários do banco $i$, entre os períodos $t$ - 1 e $t$, escalonada pelos ativos totais do início do período $t$;

$S E L_{t}$ : taxa básica de juros da economia, em termos reais, no trimestre $t$ - taxa Selic, deflacionada pelo Índice de Preços ao Consumidor Amplo (IPCA);

$P I B_{t}$ : variação do Produto Interno Bruto a valores básicos, referente ao período $t$;

$C A M_{t}$ : variação cambial real no período $t$ - taxa de câmbio livre do dólar americano (venda) - deflacionada pelo IPCA;

$I B O V_{t}$ : variação real do Ibovespa (índice da Bolsa de Valores de São Paulo), no período $t$ - deflacionada pelo IPCA;

$<T I P_{i, t}>$ : vetor de variáveis representando a proporção da carteira de TVM do banco $i$, no período $t$, aplicada em cinco categorias de investimentos: títulos públicos federais (TPF); títulos públicos estaduais ou municipais $(E S T M N)$; CDBs, letras imobiliárias e letras hipotecárias $(C D B L T)$; debêntures e ações $(D E B A C)$; e outros títulos (OUT);

$<P R Z_{i, t}>$ : vetor de variáveis representando a proporção da carteira de TVM do banco $i$, no período $t$, distribuída de acordo com o prazo de vencimento dos papéis: sem vencimento (SVC); vencimento até 12 meses (AT12M); vencimento mais de 1 e até 5 anos (AT5A); vencimento mais de 5 e até 15 anos (AT15A); vencimento superior a 15 anos $(S 15 A)$;

$<\mathrm{CON}_{i, t}>$ : vetor de variáveis representando o grau de concentração da carteira de TVM do banco $i$, no período $t$, identificando a proporção da carteira aplicada junto aos: emitentes públicos $(P U B) ; 10$ maiores emitentes privados (M10PR); 50 seguintes maiores emitentes privados $(M 50 P R) ; 100$ seguintes maiores emitentes privados $(M 100 P R)$; e demais emitentes privados (DMPR); e

$\varepsilon_{i, t}$ : é o termo de perturbação ou erro, assumindo a normalidade dos resíduos, ou seja, $\sim \mathrm{N}\left(0, \sigma^{2}\right)$, que traduz a parcela discricionária do RTVM do banco $i$, no período $t$. 
A construção do modelo para a identificação dos accruals discricionários relacionados à mensuração da carteira de TVM a valor justo considera, inicialmente, que a parcela não discricionária desse resultado é relacionada com o saldo da carteira no final do período anterior $\left(T V M_{(-1)}\right)$ e com a variação ocorrida no período presente $(\Delta T V M)$. O pressuposto analítico para a inclusão dessas variáveis é que a parcela dos resultados com TVM que seja explicada pelo saldo da carteira não pode ser entendida como uma ação discricionária da administração em sua mensuração, tendo em vista ser natural que um maior volume de recursos aplicados em títulos e valores mobiliários gere resultados mais relevantes. Gabriel e Corrar (2010) utilizam abordagem parecida, com a ressalva de que, ao invés de usarem o saldo da carteira no período anterior, utilizaram o ajuste ao valor de mercado. Outra diferença é que se concentraram especificamente na carteira de títulos para negociação e disponíveis para venda. Além das premissas analíticas destacadas e do estudo de Gabriel e Corrar (2010), a incorporação dessas variáveis se baseia, por analogia, em estudos desenvolvidos para a identificação da PCLD discricionária em bancos (Kanagaretnam, Lobo, \& Mathieu, 2003, 2004; Zenderski, 2005; Alali \& Jaggi, 2010; Kanagaretnam, Krishnan, \& Lobo, 2010), que incorporam entre as variáveis explicativas das despesas com esse tipo de provisão em determinado período: o saldo das operações vencidas no período anterior; a variação no saldo das operações vencidas; a variação no saldo da carteira de crédito; entre outras.

No que se refere, particularmente, à variável $\Delta T V M$, é importante ressaltar uma limitação decorrente do tipo de informações disponíveis. O mais apropriado seria a identificação dos valores relativos às efetivas compras/vendas dos títulos e valores mobiliários e não a variação do saldo da carteira, que inclui os ganhos e perdas do período. De qualquer forma, mesmo com essa limitação, considera-se que a variação da carteira é uma proxy adequada dos movimentos de compra e venda dos títulos e valores mobiliários no período. Para tanto, parte-se da premissa de que o comportamento dos ganhos e perdas com TVM guarda associação relativamente uniforme com o saldo da carteira. A limitação destacada reside no fato de que, em momentos de crise, esse pressuposto pode ser comprometido.

Com o propósito de aprimorar a especificação do modelo, buscando reduzir ao mínimo possível o termo de erro - que representa a parcela discricionária do RTVM - são incorporadas outras variáveis explicativas que são associadas à parcela não discricionária do resultado com TVM. Assim, além do saldo da carteira no mês anterior e da proxy das movimentações ocorridas no período, são adicionadas variáveis relativas à taxa básica de juros da economia (SEL), ao nível de crescimento da economia $(P I B)$, à variação cambial (CAM), à variação do $(I B O V)$, aos tipos de papéis que integram a carteira (TIP), aos prazos de vencimento dos títulos $(P R Z)$ e ao grau de concentração, por emissor (CON).

A justificativa para a incorporação da taxa básica de juros da economia $(S E L)$ entre as variáveis explicativas dos resultados com TVM é que, no mercado de títulos brasileiro, os títulos públicos federais têm participação relevante.
Além do mais, é esperado que uma mudança no patamar da taxa real de juros repercuta na precificação de outros papéis do mercado, por afetar as expectativas dos agentes de mercado. Por tudo isso, é assumida a premissa de que o comportamento do RTVM explicado pela variável $S E L$ não pode ser atribuído a uma ação discricionária da administração. Quanto ao sinal esperado para essa relação, são projetados efeitos distintos, dependendo da composição da carteira: para os títulos pós-fixados com rendimento vinculado à taxa Selic, uma mudança no nível de juros tem efeito positivo; para os papéis pré-fixados, a alteração no patamar dos juros da economia deve se refletir na redução do valor justo desses instrumentos financeiros. A previsão da relação entre a taxa básica de juros da economia e os resultados com TVM é inspirada em Shrieves e Dahl (2003), Agarwal, Chomsisengphet, Liu, \& Rhee (2005) e Santos (2007).

No caso da variável $P I B$, o pressuposto é que o comportamento da economia influencia o valor dos TVM, incluindo o resultado de ações mercadológicas da administração, considerando um possível trade-off com a carteira de operações de crédito. Essa premissa se baseia, por analogia, nas formulações de Shrieves e Dahl (2003) e Gray e Clarke (2004), que associaram a PCLD em instituições bancárias ao nível de atividade da economia, representado pela variação do PIB. Para o presente estudo, é considerado que, em momentos de maior dinamismo da economia, é esperado, por exemplo, que aumente a demanda por operações de crédito, o que deve se refletir em oportunidades de aplicação do funding bancário em operações mais rentáveis que os títulos e valores mobiliários, reduzindo a participação do RTVM em relação aos ativos totais. Por esse entendimento, portanto, é esperada uma relação negativa entre o resultado com TVM e o nível de atividade da economia, representado pela variação do produto interno bruto. Considera-se, para os propósitos deste estudo, que a variação no resultado com TVM que é explicada pelo comportamento da variável PIB não pode ser atribuída à ação oportunista da administração.

A inclusão da variável $C A M$ se justifica pelo propósito de capturar o impacto da variação cambial no valor justo dos títulos com esse indexador. O pressuposto é que o valor desse tipo de papel deve reagir positivamente a mudanças no nível da taxa de câmbio, não podendo se atribuir tais modificações no valor justo dos TVM à ação discricionária da administração dos bancos, até porque sobre isso ela não tem domínio. Quanto ao sinal, é esperada uma associação positiva entre as variáveis $R T V M$ e CAM. Isso se justifica pelo fato de que o impacto negativo de uma variação cambial positiva no resultado das instituições bancárias só pode ser associado às posições passivas (posição vendida) em moeda estrangeira, em particular nas operações com derivativos, e não à carteira de TVM.

Para a variável $I B O V$, considera-se que o comportamento do mercado de capitais influencie a avaliação dos títulos e valores mobiliários, até pelo fato de que os papéis ali transacionados compõem a carteira de TVM dos bancos. Por óbvio, os resultados obtidos por uma instituição bancária em sua carteira de TVM em decorrência de variações no índice do mercado de capitais não podem ser associados ao 
comportamento discricionário da administração. Esperase que a relação entre $R T V M$ e $I B O V$ seja positiva, coerente com os pressupostos de Shrieves e Dahl (2003), Agarwal et al. (2005) e Santos (2007).

No que se refere à utilização de vetores representativos de características da carteira (TIP, PRZ e CON), o presente estudo se inspira em Kanagaretnam, Krishnan e Lobo (2010) e Kanagaretnam, Lim e Lobo (2010), que utilizaram parâmetros das carteiras de crédito dos bancos para estimar a provisão para créditos de liquidação duvidosa dos bancos. Em relação ao tipo de título que compõe a carteira, $T I P$, o propósito é capturar os efeitos de diferenças de comportamento no valor justo dos TVM em decorrência da composição da carteira de cada banco, particularmente em relação ao tipo de papel e ao emissor. Quanto aos prazos dos títulos que integram a carteira, $P R Z$, a premissa é que os efeitos no valor justo dos papéis se dá de forma distinta, dependendo do prazo de vencimento, ou seja, títulos mais curtos estão menos sujeitos a risco de mercado, portanto menos suscetíveis a volatilidades decorrentes de alterações nas condições econômicas do ambiente. Para as medidas de concentração da carteira de TVM, vetor de variáveis CON, o entendimento é que, por representar uma medida de risco, é importante que se controlem os seus efeitos em relação à avaliação do valor justo da carteira, tendo em vista que uma instituição financeira que tem seus investimentos concentrados em títulos de poucos emitentes pode ter um comportamento distinto em relação à avaliação do valor justo da carteira quando comparado com um banco que tenha uma carteira diluída.

Pelas razões expostas, variações no resultado com TVM que possam ser atribuídas às características de tipo de título que compõe a carteira, do prazo desses títulos e do grau de concentração por emitente são consideradas como não discricionárias, ou seja, não podem ser atribuídas a uma ação oportunista da administração. Em relação às variáveis que compõem esses vetores não podem ser atribuídos os comportamentos esperados para cada uma delas. O propósito se limita em controlar os seus efeitos no comportamento da variável dependente, RTVM, quaisquer que sejam eles.

Em síntese, o processo de estimação da parcela não discricionária dos resultados com TVM, proposto no modelo (3.1), considera as variáveis e as relações destacadas na Tabela 3.

Tabela 3 Síntese das relações esperadas na explicação da parcela não discricionária dos resultados com TVM (RTVM), na aplicação do modelo (3.1)

\begin{tabular}{|c|c|c|}
\hline Variável & Comportamento não discricionário esperado & Sinal \\
\hline $\operatorname{TVM}(-1)$ & $\begin{array}{l}\text { O saldo da carteira de TVM no período anterior é um dos determinantes dos resultados com títulos e valores mobiliários no } \\
\text { período em questão. }\end{array}$ & + \\
\hline$\Delta T V M$ & A variação no saldo da carteira de TVM influencia o resultado com títulos e valores mobiliários do período. & + \\
\hline SEL & $\begin{array}{l}\text { A taxa básica de juros da economia, em termos reais, influencia o valor justo dos títulos e valores mobiliários e, por consequência, } \\
\text { os resultados com TVM. }\end{array}$ & ? \\
\hline$P I B$ & $\begin{array}{l}\text { O nível de atividade da economia afeta negativamente os resultados com TVM, pela oportunidade de operações mais rentáveis em } \\
\text { momentos de maior dinamismo. }\end{array}$ & - \\
\hline CAM & A variação cambial influencia positivamente os resultados com TVM, por valorizar os títulos lastreados em moeda estrangeira. & + \\
\hline IBOV & $\begin{array}{l}\text { A variação do índice do mercado de capitais afeta positivamente o valor justo dos títulos e valores mobiliários e, por } \\
\text { consequência, os resultados com TVM. }\end{array}$ & + \\
\hline TIP & $\begin{array}{l}\text { Os diferentes tipos de categorias de investimentos em TVM afetam de forma distinta os resultados com TVM, devendo ser } \\
\text { controlados. }\end{array}$ & ? \\
\hline$P R Z$ & $\begin{array}{l}\text { As diferenças de prazo de vencimento dos títulos que compõem as carteiras de TVM afetam diferentemente os resultados com } \\
\text { TVM, devendo ser controladas. }\end{array}$ & ? \\
\hline CON & $\begin{array}{l}\text { Os diferentes graus de concentração das carteiras de TVM, por emissor, afetam diferentemente os resultados com TVM, devendo } \\
\text { ser controlados. }\end{array}$ & ? \\
\hline
\end{tabular}

\subsection{Procedimento para teste de validação do modelo (3.1).}

Considerando as evidências obtidas por Zenderski (2005), Monteiro e Grateron (2006), Santos (2007) e Goulart (2007) de que as instituições bancárias brasileiras utilizaram as operações com TVM para promover o alisamento de resultados, os procedimentos adotados para a validação do modelo (3.1) compreenderão: (i) a aplicação de modelo de um estágio para a confirmação da hipótese esperada de income smoothing; e (ii) a especificação do segundo estágio do modelo (3.1) para confirmar se os resultados em relação ao alisamento de resultados são coerentes com o obtido em relação ao primeiro.

Para os propósitos de validação, portanto, será utilizado como referência o modelo (3.2) para confirmação da hipótese de alisamento de resultados.

$$
\begin{aligned}
R T V M_{i, t}= & \beta_{0}+\beta_{i}+\beta_{1}\left(L L_{i, t}-R T V M_{i, t}\right)+\beta_{2} \triangle A A P_{i, t}+ \\
& \beta_{3} T V M_{i, t}+\beta_{4} S E L_{t}+\beta_{5} P I B_{t}+\beta_{6} C A M_{t}+ \\
& \beta_{t} I B O V+\beta_{8} N A C_{i}+\beta_{9} P R V_{i}+\beta_{10} \ln A T_{i, t}+\varepsilon_{i, t}
\end{aligned}
$$

onde:

$L L_{i, t}$ : lucro líquido do banco $i$, no período $t$, escalonado pelos ativos totais do início do período $t$;

$\triangle A A P_{i, t}$ : variação na conta Ajuste de Avaliação Patrimonial do banco $i$, entre os períodos $t-1$ e $t$, escalonado pelos ativos totais do início do período $t$;

$N A C_{i}$ : variável dummy, assumindo 1 para as instituições financeiras $i$ sob controle de capital nacional e 0 para as demais; 
$P R V_{i}$ : variável dummy, assumindo 1 para as instituições financeiras $i$ de capital privado e 0 para as demais; e

$\ln A T_{i, t}$ : logaritmo natural dos ativos totais do banco $i$, no período $t$, deflacionados pelo IPCA.

Para a composição desse modelo foram consideradas variáveis utilizadas nos estudos citados nas seções 2.3 e 2.4 - em especial Shrieves e Dahl (2003) e Santos (2007), que inspiraram a inclusão das variáveis $L L-R T V M, S E L, I B O V$, $P R V$ e $\ln A T$ - e em premissas discutidas no desenvolvimento do modelo (3.1).

A hipótese do gerenciamento de resultados com o propósito de alisamento de resultados é confirmada se for evidenciada relação negativa entre a variável dependente e o lucro líquido sem o resultado com títulos e valores mobiliários ( $L L-R T V M)$. Por esse entendimento, o resultado com TVM aumenta (diminui) quando o lucro antes dos ganhos e perdas com títulos e valores mobiliários é menor (maior). A constatação de sinal negativo para a variável $\triangle A A P$, por sua vez, evidenciará que os bancos usam a classificação da carteira de disponível para vendas como instrumento de gerenciamento. Além dessas duas variáveis de interesse e do saldo da carteira (TVM), são incorporadas variáveis de controle. A taxa básica de juros (SEL), a variação cambial (CAM), o comportamento do mercado de capitais (IBOV) e o nível de crescimento da economia (PIB) são incluídos para capturar os seus efeitos na avaliação da carteira de títulos e valores mobiliários, devido aos mesmos motivos que justificaram suas inclusões no modelo (3.1). No caso das variáveis $N A C, P R V$ e $\ln A T$, o propósito é identificar e controlar a diferença de comportamento no processo de mensuração a valor justo e classificação da carteira de TVM, em razão das características das instituições financeiras, por origem do capital de controle - banco nacional ou estrangeiro e privado ou estatal - e por porte da instituição.

Considerando esse contexto, na Tabela 4, são resumidos os resultados esperados na estimação dos resultados com TVM, conforme modelo (3.2):

Tabela 4 Síntese das relações esperadas na explicação dos resultados com TVM (RTVM), na aplicação do modelo (3.2)

\begin{tabular}{|c|c|c|}
\hline Variável & Relação esperada & Sinal \\
\hline LL-RTVM & $\begin{array}{l}\text { O resultado com TVM aumenta (diminui) quando o lucro antes dos ganhos e perdas com títulos e valores mobiliários é menor } \\
\text { (maior), confirmando a hipótese de gerenciamento. }\end{array}$ & - \\
\hline$\triangle A A P$ & $\begin{array}{l}\text { O uso da classificação da carteira de disponível para vendas como instrumento de gerenciamento de resultados se reflete na } \\
\text { associação negativa entre os resultados com TVM e a variação da conta Ajuste de Avaliação Patrimonial. }\end{array}$ & - \\
\hline TVM & O saldo da carteira de TVM influencia a dimensão do resultado com títulos e valores mobiliários do período. & + \\
\hline SEL & $\begin{array}{l}\text { A taxa básica de juros da economia, em termos reais, influencia o valor justo dos títulos e valores mobiliários e, por } \\
\text { consequência, os resultados com TVM. }\end{array}$ & $?$ \\
\hline$P I B$ & $\begin{array}{l}\text { O nível de atividade da economia afeta negativamente os resultados com TVM, pela oportunidade de operações mais rentáveis } \\
\text { em momentos de maior dinamismo. }\end{array}$ & - \\
\hline CAM & A variação cambial influencia positivamente os resultados com TVM, por valorizar os títulos lastreados em moeda estrangeira. & + \\
\hline NAC & $\begin{array}{l}\text { Controle das diferenças de comportamento no processo de mensuração a valor justo e classificação da carteira de TVM por parte } \\
\text { de bancos nacionais ou estrangeiros. }\end{array}$ & $?$ \\
\hline$P R V$ & $\begin{array}{l}\text { Controle das diferenças de comportamento no processo de mensuração a valor justo e classificação da carteira de TVM por parte } \\
\text { de bancos privados ou estatais. }\end{array}$ & $?$ \\
\hline $\ln A T$ & $\begin{array}{l}\text { Controle das diferenças de comportamento no processo de mensuração a valor justo e classificação da carteira de TVM em razão } \\
\text { do porte das instituições bancárias. }\end{array}$ & $?$ \\
\hline
\end{tabular}

A etapa seguinte do processo de validação consiste em identificar a prática do income smoothing, tendo como variável dependente não o resultado total com títulos e valores mobiliários, mas sua parcela discricionária $(R T V M d)$, mensurada como o termo de erro do modelo (3.1) - o primeiro estágio. Para a identificação da hipótese de alisamento de resultados é aplicado o seguinte modelo, configurando o segundo estágio do modelo (3.1):

$$
\begin{gathered}
R T V M d_{i, t}=\beta_{0}+\beta_{i}+\beta_{1}\left(L L_{i, t}-R T V M_{i, t}\right)+\beta_{2} \Delta A A P_{i, t}+ \\
\beta_{S} N A C_{i}+\beta_{4} P R V_{i}+\beta_{5} \ln A T_{i, t}+\varepsilon_{i, t}
\end{gathered}
$$

Como se percebe, além da alteração em relação à variável dependente, o modelo (3.3) segue a mesma lógica de construção do modelo (3.2) para a identificação do gerenciamento de resultados, exceto pelo fato de eliminar as variáveis TVM,
SEL e PIB, em virtude de já terem sido consideradas na apuração da parcela não discricionária do RTVM no modelo (3.1). A confirmação da hipótese de income smoothing no modelo (3.3) é condicionada à significância estatística e sinal negativo na variável ( $L L-R T V M)$, enquanto a constatação do uso da classificação da carteira para fins de gerenciamento depende das evidências obtidas em relação à variável $\triangle A A P$, tudo de forma equivalente ao verificado em relação ao modelo (3.2).

Assim, a validação do modelo (3.1) está condicionada à identificação, no modelo (3.3), de resultados equivalentes aos apurados no modelo (3.2) para as variáveis de interesse relativas ao income smoothing. Coerente com esse pressuposto, são esperados os resultados resumidos na Tabela 5, decorrentes da estimação da parcela discricionária dos resultados com TVM, conforme modelo (3.3). 
Tabela 5

Síntese das relações esperadas na explicação da parcela discricionária dos resultados com TVM (RTVMd), na aplicação do modelo (3.3)

\begin{tabular}{|c|c|c|}
\hline Variável & Relação esperada & Sinal \\
\hline LL-RTVM & $\begin{array}{l}\text { A discricionariedade no RTVM aumenta (diminui) quando o lucro antes dos ganhos e perdas com TVM é menor (maior), confirman- } \\
\text { do a hipótese de gerenciamento. }\end{array}$ & - \\
\hline$\triangle A A P$ & $\begin{array}{l}\text { O uso da classificação da carteira de disponível para vendas como instrumento de gerenciamento de resultados se reflete na asso- } \\
\text { ciação negativa entre a discricionariedade do RTVM e a variação da conta Ajuste de Avaliação Patrimonial. }\end{array}$ & - \\
\hline$N A C$ & $\begin{array}{l}\text { Controle das diferenças de comportamento no processo de mensuração a valor justo e classificação da carteira de TVM por parte de } \\
\text { bancos nacionais ou estrangeiros. }\end{array}$ & $?$ \\
\hline$P R V$ & $\begin{array}{l}\text { Controle das diferenças de comportamento no processo de mensuração a valor justo e classificação da carteira de TVM por parte de } \\
\text { bancos privados ou estatais. }\end{array}$ & ? \\
\hline $\ln A T$ & $\begin{array}{l}\text { Controle das diferenças de comportamento no processo de mensuração a valor justo e classificação da carteira de TVM em razão } \\
\text { do porte das instituições bancárias. }\end{array}$ & $?$ \\
\hline
\end{tabular}

\subsection{Amostra.}

A realização dos testes empíricos tem por base os dados das Informações Financeiras Trimestrais dos bancos comerciais, bancos múltiplos e caixas econômicas, integrantes do Sistema Financeiro Nacional (SFN), considerando o período entre o terceiro trimestre de 2002 e o quarto trimestre de 2010. A restrição do período inicial da amostra se justifica pelo propósito de evitar os efeitos da adoção inicial dos critérios de classificação e de avaliação dos TVM previstos na Circular BCB 3.068/2001. A ideia é trabalhar com dados produzidos após o encerramento do primeiro balanço semestral após a vigência da norma, de modo a evitar eventuais "ruídos" provocados pelos ajustes no saldo da carteira, no primeiro momento da adoção da norma.
Considerando os parâmetros de definição da amostra e as Informações Financeiras Trimestrais divulgadas na página do BCB na internet, foram considerados dados de 207 bancos comerciais, bancos múltiplos e caixas econômicas. $\mathrm{Na}$ análise preliminar dos dados foram identificadas algumas observações que constituem fortes indícios de inconsistência ou de situações muito especiais, geralmente associados a momentos de início ou de descontinuidade das operações das instituições. Para evitar o risco de os resultados dos testes serem contaminados por situações anômalas representativas de clara desproporção entre os resultados e os ativos aplicados, foram excluídas 16 observações (todas elas distando pelo menos quatro desvios padrões em relação à média) da base de dados, resultando em 5.827 observações banco/trimestre.

\section{RESULTADOS}

Como pré-condição para assegurar a robustez dos resultados decorrentes da aplicação dos modelos (3.1), (3.2) e (3.3), foram realizados testes $I m$, Pesaran e Shin de raízes unitárias, conforme Tabela A.1 (anexos) para verificar a condição de estacionariedade das séries não dicotômicas, sendo rejeitada a hipótese nula da presença de raiz unitária em todas elas. É eliminado, assim, o risco de regressões espúrias.

Também preliminarmente à aplicação dos modelos foi elaborada Matriz de Correlação de Pearson entre os regressores, conforme Tabelas A.2 e A.3 (anexos), com o fim de verificar a existência de correlação entre as variáveis explicativas dos modelos testados, que poderiam refletir problemas de alto grau de multicolinearidade - podendo resultar, inclusive, em alteração dos sinais dos coeficientes das variáveis de interesse. É considerada a regra prática sugerida por Kennedy (1998) de que o risco de multicolinearidade é um problema sério quando os coeficientes de correlação entre os regressores são altos - maiores que 0,8 . Foi identificado um caso de elevado coeficiente de correlação, próximo a esse limite - a correlação positiva de 0,78 entre as aplicações em títulos públicos federais $(T P F)$ e a concentração da carteira em títulos públicos $(P U B)$, que se justifica pela pouca representatividade dos títulos estaduais e municipais. Sendo assim, para mitigar o risco de multicolinearidade nos resultados, na aplicação dos modelos (3.1) e (3.2) é evitada a consideração dessas variáveis concomitantemente.

\subsection{Especificação da Parcela Não Discricionária do Resultado com TVM.}

Uma primeira condição para se concluir pela consistência do modelo de dois estágios proposto é que os resultados em relação às variáveis explicativas, no primeiro estágio, sejam consistentes com as perspectivas teóricas. Para esse fim, foi promovida a especificação da parcela não discricionária do resultado com títulos e valores mobiliários, com a aplicação do modelo (3.1), com a utilização do método de dados em painel com efeitos fixos seccionais, cujos resultados são demonstrados na Tabela 6. 

da discricionariedade dos resultados com TVM.

\begin{tabular}{|c|c|c|c|c|c|c|c|c|c|}
\hline \multicolumn{10}{|c|}{ Modelo testado: } \\
\hline \multicolumn{10}{|c|}{$R T V M_{i, t}=\beta_{0}+\beta_{i}+\beta_{1} T V M_{i, t-1}+\beta_{2} \Delta T V M_{i, t}+\beta_{3} S E L_{t}+\beta_{4} P I B_{t}+\beta_{5} C A M_{t}+\beta_{6} I B O V+\psi_{1}<T I P_{i, t}>+\psi_{2}<P R Z_{i, t}>+\psi_{3}<\operatorname{CON}_{i, t}>+\varepsilon_{i, t}$} \\
\hline Const & $\operatorname{TVM}(-1)$ & $\Delta T V M$ & SEL & $P I B$ & CAM & $I B O V$ & $T P F$ & ESTMN & $C D B L T$ \\
\hline 0.013 & 0.019 & 0.025 & 0.024 & -0.045 & 0.030 & 0.004 & 0.002 & -0.023 & 0.001 \\
\hline$(0.000)$ & $(0.000)$ & $(0.000)$ & $(0.659)$ & $(0.065)$ & $(0.000)$ & $(0.536)$ & $(0.141)$ & $(0.392)$ & $(0.876)$ \\
\hline \multirow[t]{10}{*}{$* * *$} & $* * *$ & $* * *$ & & $*$ & $* * *$ & & & & \\
\hline & $D E B A C$ & $S V C T$ & AT12M & AT5A & AT15A & M1OPR & M5OPR & M100PR & $D M P R$ \\
\hline & 0.004 & -0.002 & -0.002 & -0.002 & -0.003 & 0.001 & 0.001 & -0.004 & -0.004 \\
\hline & $(0.166)$ & (0.159) & $(0.153)$ & $(0.155)$ & $(0.107)$ & $(0.517)$ & (0.954) & $(0.818)$ & $(0.326)$ \\
\hline & \multicolumn{9}{|c|}{ Período: $4^{\circ}$ trim $/ 2002$ ao $4^{\circ}$ trim $/ 2010$} \\
\hline & № observações: & 5.823 & & & & & No bancos: & 207 & \\
\hline & $R^{2}:$ & 0.2979 & & & & & Estatística F: & 10.6071 & \\
\hline & $\mathrm{R}^{2}$ ajustado: & 0.2699 & & & & & p-valor (F): & 0.0000 & \\
\hline & Estatística DW: & 1.6468 & & & & & te Hausman: & 38.7266 & \\
\hline & Teste de Chow: & 6.8083 & & & & & r (Hausman) & 0.0031 & \\
\hline
\end{tabular}

onde: RTVM é o resultado com títulos e valores mobiliários, escalonado pelos ativos totais do início do período; TVM o saldo da carteira de títulos e valores mobiliários, escalonado pelos ativos totais do início do período; $\triangle T V M$ a variação na carteira de títulos e valores mobiliários, escalonada pelos ativos totais do início do período; SEL a taxa básica de juros da economia, em termos reais; PIB a variação do Produto Interno Bruto a valores básicos; CAM a variação cambial real; IBOV a variação real do ; TIP a proporção da carteira de TVM aplicada em cinco categorias de investimentos - títulos públicos federais (TPF), títulos públicos estaduais ou municipais $(E S T M N)$, CDBs, letras imobiliárias e letras hipotecárias (CDBLT), debêntures e ações $(D E B A C)$ e outros títulos $(O U T)$-; PRZ a proporção da carteira de TVM distribuída de acordo com o prazo de vencimento dos papéis - sem vencimento (SVCT), até 12 meses $(A T 12 M)$, mais de 1 e até 5 anos (AT5A), mais de 5 e até 15 anos (AT15A) e superior a 15 anos (S15A) -; e CON o grau de concentração da carteira de TVM, identificando a proporção da carteira aplicada junto aos - emitentes públicos $(P U B), 10$ maiores emitentes privados (M10PR), 50 seguintes maiores emitentes privados (M50PR), 100 seguintes maiores emitentes privados (M100PR) e demais emitentes privados (DMPR).

Legenda para a significância dos parâmetros: a 1\%(***); a 5\%(**); e a $10 \%\left({ }^{*}\right)$.

De acordo com o previsto na Seção 3.1, foram encontrados parâmetros positivos estatisticamente relevantes para as variáveis $T V M(-1)$ e $\triangle T V M$, indicando que os resultados com TVM são relacionados com a dimensão dos recursos aplicados na carteira, o que não pode ser atribuído a uma ação discricionária da administração. Também foi constatada relação positiva entre o $R T V M$ e a variável representativa da variação cambial (CAM), confirmando as expectativas destacadas no desenvolvimento do modelo. Para a variável PIB foi identificada relação negativa, indicando que em momentos de maior crescimento econômico há um decréscimo do resultado relativo com TVM, o que pode ser justificado pelo trade-off com as operações de crédito, ou seja, em períodos de maior dinamismo da economia pode ocorrer uma transferência natural de recursos para operações de crédito, reduzindo a participação do RTVM em relação aos ativos totais.

Para a variável $I B O V$ não foi confirmada a expectativa de relação positiva com o $R T V M$, o que pode ser explicado, eventualmente, por uma menor participação dos títulos mobiliários na composição da carteira. No caso da variável $S E L$, não foi encontrada relação estatisticamente relevante, evidenciando a dicotomia destacada na Seção 3.1 de que a variação na taxa de juros pode ter efeitos distintos no valor justo dos títulos, dependendo se ele é pós-fixado baseado na Selic ou pré-fixado.

Também foram controlados os efeitos dos tipos, prazos e graus de concentração da carteira de títulos e valores mobiliários. Nas evidências empíricas apuradas não foram encontradas relações estatisticamente significantes entre o resultado com TVM e as variáveis que compõem os vetores TIP, $P R Z$ e CON. Uma potencial explicação para esse tipo de situação pode ser o detalhamento desses vetores. Adicionalmente, cabe ressaltar que para a especificação da parcela não discricionária é considerada, além dos coeficientes das variáveis e da constante, a parcela dos efeitos fixos seccionais $\left(\beta_{i}\right)$. O termo de erro corresponde à parcela discricionária do RTVM.

\subsection{Identificação do Income Smoothing com Modelo de um Estágio.}

O primeiro procedimento de teste consiste em aplicar o modelo (3.2) para identificar a hipótese de alisamento de resultados, por parte das instituições financeiras brasileiras, com o uso de TVM. Os resultados apurados são consolidados na Tabela 7. 


\section{Modelo testado:}

$R T V M_{i, t}=\beta_{0}+\beta_{i}+\beta_{t}\left(L L_{i, t}-R T V M_{i, t}\right)+\beta_{2} \Delta A A P_{i, t}+\beta_{3} T V M_{i, t}+\beta_{4} S E L_{t}+\beta_{5} P I B_{t}+\beta_{6} C A M_{t}+\beta_{7} I B O V+\beta_{8} N A C_{i}+\beta_{9} P R V_{i}+\beta_{10} \ln A T_{i, t}+\varepsilon_{i, t}$

\begin{tabular}{cccccccc}
\hline Const & LL-RTVM & $\triangle A A P$ & TVM & SEL & PIB & CAM & IBOV \\
\hline 0.018 & -0.226 & -0.111 & 0.023 & 0.005 & -0.026 & 0.025 & 0.004 \\
$(0.025)$ & $(0.000)$ & $(0.076)$ & $(0.000)$ & $(0.893)$ & $(0.134)$ & $(0.000)$ & $(0.332)$ \\
$* *$ & $* * *$ & $*$ & $* * *$ & & & & $* * *$ \\
\hline & NAC & $P R V$ & $\ln A T$ & & & & \\
& 0.001 & 0.011 & -0.001 & & & \\
& $(0.700)$ & $(0.028)$ & $(0.003)$ & & & & \\
& & $* * * *$ & & &
\end{tabular}

Período: $\quad 3^{\circ}$ trim $/ 2002$ ao $4^{\circ}$ trim $/ 2010$

$\begin{array}{rc}\text { No observações: } & 5.827 \\ \mathrm{R}^{2}: & 0.4177 \\ \mathrm{R}^{2} \text { ajustado: } & 0.3953 \\ \text { Estatística DW: } & 1.6759 \\ \text { Teste de Chow: } & 7.5115\end{array}$

$\begin{array}{rr}\text { No bancos: } & 206 \\ \text { Estatística F: } & 18.7183 \\ \text { p-valor (F): } & 0.0000 \\ \text { Teste Hausman: } & 34.9058 \\ \text { p-valor (Hausman) } & 0.0001\end{array}$

onde: RTVM é o resultado com títulos e valores mobiliários, escalonado pelos ativos totais do início do período; $L L$ o lucro líquido, escalonado pelos ativos totais do início do período; $\triangle A A P$ a variação na conta Ajuste de Avaliação Patrimonial, escalonado pelos ativos totais do início do período; TVM o saldo da carteira de títulos e valores mobiliários, escalonado pelos ativos totais do início do período; SEL a taxa básica de juros da economia, em termos reais; PIB a variação do Produto Interno Bruto a valores básicos; CAM a variação cambial real; IBOV a variação real do ; NAC assume 1 para as instituições financeiras sob controle de capital nacional e 0 para as demais; $P R V$ assume 1 para as instituições financeiras de capital privado e 0 para as demais; e $\ln A T$ o logaritmo natural dos ativos totais.

Legenda para níveis de significância dos parâmetros: a $1 \%\left({ }^{* * *}\right)$; a $5 \%\left({ }^{* *}\right)$; e a $10 \%\left(^{*}\right)$.

A significância estatística e o sinal negativo da variável (LL-RTVM) na explicação da variável $R T V M$ estão de acordo com a hipótese de utilização dos resultados com títulos e valores mobiliários para a promoção do alisamento de resultados, coerente com Zenderski (2005), Monteiro e Grateron (2006), Santos (2007) e Goulart (2007). A relação estatisticamente relevante e inversa entre a variável explicada e $\triangle A A P$ evidencia que os bancos usam a classificação da carteira disponível para vendas nessas ações discricionárias de gerenciamento.

Em relação às variáveis de controle, foram constatadas relações positivas entre o RTVM e: (i) o saldo da carteira de títulos e valores mobiliários, o que era natural e previsível; (ii) a variação cambial, evidenciando sua relevância na avaliação da carteira, como decorrência de ser parâmetro de remuneração de alguns títulos; e (iii) a condição de a instituição financeira ser privada, demonstrando que esses bancos registram maiores resultados com TVM que as entidades sob controle estatal. Também foi constatada relação inversa entre o RTVM e o porte das instituições, representada por $\ln A T$, indican- do que os bancos menores registram maior proporção de resultados com TVM em relação aos ativos totais. Para as variáveis $S E L, P I B$ e NAC não foram identificados parâmetros relevantes, evidenciando que os efeitos líquidos da taxa básica de juros reais da economia, do nível de atividade econômica e do fato de o capital de controle da instituição ter participação estrangeira ou não nos resultados com TVM não são relevantes.

\subsection{Identificação do Income Smoothing com o Modelo de Dois Estágios.}

O processo de validação do modelo de dois estágios desenvolvido no presente estudo tem como principal parâmetro a comparação dos seus resultados com os encontrados no modelo de um estágio, destacados na Seção 4.2. Com isso é testada a hipótese do income smoothing no mercado bancário brasileiro, com o uso de TVM, utilizando-se o modelo de dois estágios (3.3), em que a variável dependente, RTVMd, corresponde ao termo de erro do modelo (3.1). Os resultados desse teste são consolidados na Tabela 8 . 
Modelo testado:

$R T V M d_{i, t}=\beta_{0}+\beta_{i}+\beta_{1}\left(L L_{i, t}-R T V M_{i, t}\right)+\beta_{2} \Delta A A P_{i, t}+\beta_{S} N A C_{i}+\beta_{4} P R V_{i}+\beta_{5} \ln A T_{i, t}+\varepsilon_{i, t}$

\begin{tabular}{ccccccc}
\hline Const & LL-RTVM & SAAP & NAC & PRV & InAT \\
\hline 0.011 & -0.224 & -0.105 & 0.001 & 0.008 & -0.001 \\
& $(0.166)$ & $(0.000)$ & $(0.087)$ & $(0.825)$ & $(0.086)$ & $(0.001)$ \\
$* * *$ & $*$ & $*$ & $*$ \\
\hline
\end{tabular}

Período: $\quad 3^{\circ}$ trim $/ 2002$ ao $4^{\circ}$ trim $/ 2010$

$\begin{array}{rrrr}\text { No observações: } & 5.817 & N^{\circ} \text { bancos: } & 206 \\ R^{2}: & 0.1650 & \text { Estatística F: } & 5.2770 \\ R^{2} \text { ajustado: } & 0.1338 & \text { p-valor (F): } & 0.0000 \\ \text { Estatística DW: } & 1.7098 & \text { Teste Hausman: } & 235.5947 \\ \text { Teste de Chow: } & 1.3941 & \text { p-valor (Hausman) } & 0.0000\end{array}$

onde: RTVMd é a parcela discricionária do resultado com títulos e valores mobiliários, escalonado pelos ativos totais do início do período, correspondente ao termo de erro decorrente da aplicação do modelo (3.1); LL o lucro líquido, escalonado pelos ativos totais do início do período; RTVM é o resultado com títulos e valores mobiliários, escalonado pelos ativos totais do início do período; $\triangle A A P$ a variação na conta Ajuste de Avaliação Patrimonial, escalonado pelos ativos totais do início do período; NAC assume 1 para as instituições financeiras sob controle de capital nacional e 0 para as demais; $P R V$ assume 1 para as instituições financeiras de capital privado e 0 para as demais; e $\ln A T$ o logaritmo natural dos ativos totais.

Legenda para a significância dos parâmetros: a $1 \%\left({ }^{* * *}\right)$; a $5 \%(* *)$; e a $10 \%(*)$

Quanto aos resultados apurados em relação às variáveis de interesse, a significância estatística e o sinal negativo das variáveis (LL-RTVM) e $\triangle A A P$ evidenciam resultados equivalentes aos encontrados com o modelo de um estágio (Tabela 7), reforçando a hipótese de gerenciamento de resultados, com o propósito de alisamento, com o uso de TVM, incluindo a possibilidade de classificação de títulos e valores mobiliários na categoria de disponíveis para venda. O raciocínio implícito nesses modelos é que os bancos aumentam discricionariamente o resultado com TVM, utilizando a subjetividade na avaliação ou na classificação da carteira (disponíveis para venda) para aumentar (ou diminuir) o lucro, com o objetivo de evitar variações acentuadas que possam transmitir ao mercado uma maior percepção de risco.

Em relação às variáveis de controle, foi constatado que as administrações dos bancos de maior porte $(\ln A T)$ são menos propensas a adotar ações discricionárias em relação aos resultados com TVM. Também foi constatado que essa prática é mais comum entre os bancos privados. Não foram identificadas diferenças relevantes no que se refere à adoção de discricionariedade na mensuração dos títulos e valores mobiliários, entre bancos sob controle de capital nacional ou estrangeiro.

Como principal conclusão desses testes, constata-se que o modelo (3.1), construído para identificar a parcela discricionária do $R T V M$, é robusto em relação ao seu propósito, pois consegue identificar o gerenciamento de resultados, de forma equivalente ao que tinha ocorrido com o modelo de um estágio - método amplamente difundido na literatura para verificar o income smoothing com o uso de títulos e valores mobiliários.

\subsection{Procedimentos para Assegurar a Robustez dos Testes.}

Além dos testes de raízes unitárias e das ações para mitigar o risco de multicolinearidade, outros procedimentos técnicos foram adotados para assegurar a robustez dos resultados. Para avaliar a existência de efeitos individuais, o que justifica o uso dos dados em painel, foi realizado o teste sugerido por Baltagi (2008), que recebe a denominação de Chow test pela similaridade com o teste de quebra estrutural. Conforme estatísticas incorporadas nas Tabelas 6, 7 e 8, foi rejeitada a hipótese nula de que os resultados apurados sem a consideração da heterogeneidade individual seriam apropriados, demonstrando a relevância da utilização dos dados em painel para o provimento de evidências com maior poder informacional, na aplicação dos modelos em questão.

Para a definição do método de dados em painel a ser utilizado, modelos fixos ou aleatórios, foi realizado o teste de Hausman para os três modelos especificados, conforme estatísticas incorporadas nas Tabelas 6, 7 e 8. A hipótese nula de que os estimadores dos modelos de efeitos fixos e de efeitos aleatórios não diferem substancialmente é re- 
jeitada, tornando imprópria a utilização do método com efeitos aleatórios. Por essa razão, é utilizado o método com efeitos fixos. Além do mais, segundo Gujarati (2006), a premissa subjacente ao modelo com efeitos aleatórios é que os erros são extrações aleatórias de uma população muito maior, o que não é o caso do presente estudo, que considera o conjunto das instituições bancárias de interesse.

Por fim, não obstante a adoção do escalonamento das variáveis $R T V M, T V M, \triangle T V M$, (LL-RTVM) e $\triangle A A P$ pelos ativos totais do início do período para mitigar o risco de heteroscedasticidade e as estatísticas do teste DurbinWatson, destacadas nas Tabelas 6, 7 e 8, terem se situado na zona "inconclusiva", na aplicação dos modelos foi utilizado, por precaução, o método de efeitos fixos cross-section SUR (PCSE) de dados em painel, para gerar resultados robustos, mesmo na presença de autocorrelação e de heteroscedasticidade nos resíduos.

\section{CONCLUSÃO}

Este estudo teve como propósito desenvolver e validar um modelo de dois estágios para a identificação da discricionariedade das acumulações com TVM pelas instituições bancárias. O desenvolvimento do modelo proposto se baseou: nos preceitos de alguns poucos estudos sobre o tema; na incorporação, por analogia, de parâmetros utilizados nos modelos de dois estágios utilizados para a identificação da PCLD discricionária em bancos; e na consideração de indicadores macroeconômicos que possam ser associados à avaliação dos papéis e de características específicas sobre a carteira de TVM de cada banco.

Os procedimentos empíricos se concentraram no processo de validação desse modelo. Para tal fim, foram cotejados os seus resultados com os apurados com a utilização de um modelo de um estágio - tendo em vista a consolidação, na literatura, desse tipo de metodologia para a análise de gerenciamento de resultados em bancos com o uso de TVM. Como referência, foi definido um modelo de identificação da prática de alisamento de resultados, considerando que estudos anteriores já haviam constatado esse tipo de gerenciamento de resultados por parte das instituições bancárias no Brasil, com o uso de títulos e valores mobiliários.

Os testes foram realizados com as informações trimestrais dos bancos comerciais, bancos múltiplos e caixas econômicas entre o terceiro trimestre de 2002 e o quarto trimestre de 2010. Utilizando, inicialmente, o modelo de referência de um estágio, foram confirmadas relações negativas e estatisticamente relevantes do resultado com títulos e valores mobiliários e: o lucro antes da incorporação do resultado com TVM, coerente com a hipótese identificada em trabalhos anteriores de utilização da carteira para fins de alisamento de resultados; e a variação da conta Ajuste de Avaliação Patrimonial, que acumula as variações no valor dos títulos classificados como disponíveis para venda, indicando que os bancos utilizam esse tipo de classificação nas suas ações de gerenciamento.

Em seguida, foi testado o modelo proposto de dois estágios, isolando a parcela discricionária do resultado com
Os coeficientes de determinação $\left(R^{2}\right)$ ajustados das regressões, destacados nas Tabelas 6, 7 e 8, demonstram que os modelos (3.1), (3.2) e (3.3) explicam 26,99\%, 39,53\% e $13,38 \%$ do comportamento das variáveis dependentes correspondentes, cabendo ressaltar, porém, que não é adequado se promover a comparação entre os graus de determinação dos modelos de um e de dois estágios. Isso porque o modelo de um estágio, cujos resultados são consolidados na Tabela 7, explicam o RTVM total, enquanto o modelo de dois estágios isola e avalia os determinantes apenas da parte discricionária desse resultado com títulos e valores mobiliários, conforme Tabela 8. De se ressaltar, adicionalmente, que a contribuição do modelo de dois estágios não reside necessariamente em sua superioridade em relação ao de um estágio, mas na validação de um instrumento que possibilite a solução de problemas de pesquisa que dependam da identificação da parcela discricionária do RTVM.

TVM. Os resultados demonstraram que a discricionariedade no RTVM é negativamente relacionada com o lucro antes do resultado com títulos e valores mobiliários e com a variação dos ajustes de avaliação patrimonial. Assim, os resultados obtidos com o modelo desenvolvido são coerentes com os encontrados no modelo de referência, ou seja: a confirmação de que os bancos brasileiros usam os resultados com TVM para o propósito de alisamento de resultados e de que a classificação na carteira de disponíveis para venda é usada nessas ações discricionárias.

A principal conclusão obtida nesses testes é a validação do modelo construído para identificar a parcela discricionária do resultado com títulos e valores mobiliários. Constata-se que ele é robusto em relação ao seu propósito, tendo em vista que consegue identificar o gerenciamento de resultados, de forma equivalente ao que tinha ocorrido com o modelo de um estágio, utilizado como referência.

Como contribuição, o desenvolvimento de um modelo de dois estágios cria condições para o desenvolvimento de pesquisas sobre o tema que se preocupem não apenas em constatar se há a prática ou não do gerenciamento de resultados, mas também associá-la a outras variáveis. No presente estudo, por exemplo, a aplicação do modelo de referência de um estágio permitiu constatar evidências da prática do alisamento de resultados e da utilização da classificação da carteira para esse fim. Considerando as variáveis de controle, até se verifica que os bancos privados e os de menor porte registram resultados com TVM, relativizados pelos ativos totais, em dimensões mais relevantes que os bancos sob controle estatal e os de maior porte, mas isso não permite inferir que haja maior ou menor manipulação. No caso do modelo de dois estágios, além de confirmar as mesmas evidências em relação à prática do alisamento e da utilização da classificação dos títulos para esse fim, também permite constatar que essa prática de gerenciamento é mais comum nos bancos de menor porte e nos controlados por capital privado, por apresentarem parcela discricionária mais relevante. Essa diferença nas evidências se justifica 
pelo fato de, no modelo de um estágio, a variável dependente ser o resultado com TVM, enquanto, no segundo estágio do modelo de dois estágios, a variável dependente ser a parcela discricionária do resultado com TVM.

Em síntese, a contribuição essencial do estudo é o desenvolvimento de um instrumento que permite a verificação de outras questões de pesquisa, não possíveis com modelos de um estágio, tais como: Que tipo de instituição apresenta mais propensão ao gerenciamento de resultados? Os mecanismos de governança corporativa da instituição influenciam na prática do gerenciamento de resultados? A política de bônus por resultados pode influenciar a prática do gerenciamento de resultados com TVM nos bancos?

Como limitação, há de se destacar, inicialmente, que esse modelo de dois estágios foi desenvolvido considerando as especificidades das instituições financeiras na gestão de uma carteira de títulos e valores mobiliários, não podendo ser automaticamente utilizado em outro contexto, sem as devidas adaptações. Outra limitação é que o estudo não se propõe a concluir sobre a superioridade do modelo proposto em relação a outros da literatura. A não realização de testes nesse sentido se justifica pelos seguintes argumentos: (i) não é tecnicamente apropriada a comparação de resultados entre modelos de um e de dois estágios; e (ii) os poucos modelos de dois estágios encontrados na literatura para a identificação da prática de gerenciamento de resultados com TVM, destacados na Tabela 2, utilizam variáveis dependentes distintas, tornando inapropriada a comparação de seus resultados.

Também há de se ressaltar as limitações implícitas nos estudos sobre gerenciamento de resultados, destacadas na literatura, notadamente quanto à capacidade dos modelos econométricos estimarem objetivamente a discricionariedade da administração. Embora este estudo avance nesse propósito, há a possibilidade de que o termo de erro do modelo proposto para isolar a discricionariedade contenha parcelas não discricionárias não identificadas. A indisponibilidade de informações públicas analíticas sobre as movimentações da carteira de TVM, que poderiam propiciar o aprimoramento da estimação dos modelos de discricionariedade dos resultados com TVM, como a composição das carteiras de títulos e valores mobiliários em relação aos níveis da hierarquia de valor justo, também pode ser entendida como uma limitação do estudo.

Por fim, a título de sugestão para futuras pesquisas, recomenda-se que o modelo aqui desenvolvido seja validado para outros tipos de práticas de gerenciamento, que não o alisamento de resultados.

\section{Referências}

Agarwal, S., Chomsisengphet, S., Liu, C., \& Rhee, G. (2005, January). Earnings management behaviors under different economic environments: evidence from Japanese banks. SSRN Working Papers. Recuperado em 8 junho, 2012, de http://papers.ssrn.com/sol3/papers. cfm? abstract_id $=654443$.

Alali, F., \& Jaggi, B. (2010, March). Earnings versus capital ratios management: role of bank types and SFAS 114. Review of Quantitative Finance and Accounting. 36 (1), 105-132.

Baggio, D. K., Monteiro, J. C. P., \& Toda, A. C. (2007, Jul./Dez.). Análisis de la volatilidad de los fondos propios en la banca brasileña: un estudio de la valoración por valor razonable. Revista Contabilidade e Informação. 27 (10), 15-24.

Baltagi, B. H. (2008). Econometric analysis of panel data. (4th. ed.). West Sussex, UK: John Wiley.

Beatty, A., Chamberlain, S. L., \& Magliolo, J. (1995). Managing financial reports of commercial banks: the influence of taxes, regulatory capital and earnings. Journal of Accounting Research. 33 (2), 231-261.

Beatty, A., \& Harris, D. G. (1999). The effects of taxes, agency costs and information asymmetry on earnings management: A comparison of public and private firms. The Review of Accounting Studies. 4 (3\&4), 299-326.

Beatty, A., Ke, B., \& Petroni, K. R. (2002, July). Earnings management to avoid earnings declines across publicly and privately held banks. The Accounting Review. 77 (3), 547-570.

Bernard, V. L., \& Skinner, D. J. (1996). What motivates managers' choice of discretionary accruals? Journal of Accounting and Economics. 22 (1-3), 313-325.

Cheng, Q., Warfield, T., \& Ye, M. (2011, April). Equity incentives and earnings management: evidence from the banking industry. Journal of Accounting, Auditing and Finance. 26 (2), 317-349.

Circular 3.068, de 8 de novembro de 2001. (2001). Estabelece critérios para registro e avaliação contábil de títulos e valores mobiliários. Banco Central do Brasil (BCB).

Cornett, M. M., McNutt, J. J., \& Tehranian, H. (2006, July). Corporate governance and earnings management at large U.S. bank holding companies. Working Paper Series WCRFS, 06-26.

DeAngelo, L. E. (1986, July). Accounting numbers as market valuation substitutes: a study of management buyouts of public stockholders. The Accounting Review. 61 (3), 400-420.

Dechow, P., Sloan, R., \& Sweeney, A. (1995). Detecting earnings management. The Accounting Review. 70 (2), 193-225.
Demski, J. S. (2005, August). Analytic modeling in management accounting research. Working Paper. The Handbook of Management Accounting Research. Recuperado em 23 março, 2012, de http://www. ohio-state.edu/ young_53/AnaliticModeling.pdf.

Fiechter, P., \& Meyer, C. (2010, July). Big bath accounting using fair value measurement discretion during the financial crisis. SSRN Working Papers. Recuperado em 5 dezembro, 2010, de http://papers.ssrn.com/ sol3/papers.cfm?abstract_id=1522122.

Fields, T. D., Lys, T. Z., \& Vincent, L. (2001). Empirical research on accounting choice. Journal of Accounting and Economics. 31 (1-3), 255-307.

Gabriel, F., \& Corrar, L. J. (2010, maio-agosto). Gerenciamento de resultados e de capital no sistema bancário brasileiro - uma investigação empírica nas aplicações em títulos e valores mobiliários. Revista de Contabilidade do Mestrado em Ciências Contábeis da UERJ. Rio de Janeiro, 15 (2), 49-62.

Goldberger, A. S. (1961). Stepwise least squares: residual analysis and specification error. Journal of the American Statistical Association. 56 (296), 998-1000.

Goulart, A. M. C. (2007). Gerenciamento de resultados contábeis em instituições financeiras no Brasil. Tese de doutorado, Programa de PósGraduação em Contabilidade - Universidade de São Paulo/USP, São Paulo, Brasil. 219 p.

Gujarati, D. N. (2006). Econometria básica (4. ed.). São Paulo: Campus.

Gray, R. P., \& Clarke, F. L. (2004). A methodology for calculating the allowance for loan losses in commercial banks. Abacus. 40 (3), 321341.

Healy, P. M. (1985, April). The effect of bonus schemes of accounting decisions. Journal of Accounting and Economics. 7 (1-3), 85-107.

Healy, P. M. (1996). Discussion of a market-based evaluation of discretionary accrual models. Journal of Accounting Research. 34 (Supplement), 107-115.

Healy, P. M., \& Wahlen, J. M. (1999). A review of the earnings management literature and its implications for standard setting. Accounting Horizons. 13 (4), 365-384.

International Federation of Accountants. IFAC. (2008, October). Challenges in auditing fair value accounting estimates in the current market environment. Staff audit practice alert. New York: IFAC.

Jones, J. (1991). Earnings management during import relief investigations. Journal of Accounting Research. 29 (2), 193-228.

Jones, K. L., Krishnan, G. V., \& Melendrez, K. D. (2008). Do models of 
discretionary accruals detect actual cases of fraudulent and restated earnings? an empirical evaluation. Contemporary Accounting Research. 25 (2), 499-531.

Kanagaretnam, K., Krishnan, G., Lobo, G. J. (2010). An empirical analysis of auditor independence in the banking industry. The Accounting Review. 85 (6), 2011-2046.

Kanagaretnam, K., Lim, C. Y., \& Lobo, G. J. (2010). Auditor reputation and earnings management: international evidence from the banking industry. Journal of banking and Finance. 34 (10), 2318-2327.

Kanagaretnam, K., Lobo, G. J., \& Mathieu R. (2003). Managerial incentives for income smoothing through bank loan loss provision. Review of Quantitative Finance and Accounting. 20 (1), 63-80.

Kanagaretnam, K., Lobo, G. J., \& Mathieu, R. (2004). Earnings management to reduce earnings variability: evidence from bank loan loss provisions. Review of Accounting \& Finance. 3 (1), 128

Kang, S., \& Sivaramakrishnan, K. (1995). Issues in testing earnings management and an instrumental variable approach. Journal of Accounting Research. 33 (2), 353-367.

Kennedy, P. (1998). A guide to econometrics. (4th, ed.). Cambridge, Mass.

Kothari, S. P. (2001). Capital markets research in accounting. Journal of Accounting and Economics. 31 (1-3), 105-231.

Lobo, G. J., Yang, D. H. (2001). Bank manager's heterogeneous decisions on discretionary loan loss provisions. Review of Quantitative Finance an Accounting. 16 (3), 223-250.

Marcondes, D. A. (2008). Disciplina de mercado e as acumulacões contábeis discricionárias. Tese de doutorado, Programa de PósGraduação em Contabilidade, Universidade de São Paulo, São Paulo, Brasil.

Martinez, A. L. (2001). Gerenciamento dos resultados contábeis: estudo empírico das companhias abertas brasileiras. Tese de doutorado, Programa de Pós-Graduação em Contabilidade, Universidade de São Paulo, São Paulo, Brasil. 167 p.

McNichols, M. (2000). Research design issues in earnings management. Journal of Accounting and Public Policy. 19 (4-5), 313-345,

Monteiro, J. C., \& Grateron, I. R. G. (2006). Impacto de la aplicacion del fair value en la volatilidad de la banca brasileña: um estúdio empírico. Revista de Contabilidade e Finanças. São Paulo, USP, 17 (40), 102-119.

Moyer, S. E. (1990, July). Capital adequacy ratio regulations and accounting choices in commercial banks. Journal of Accounting and Economics. 13 (2), 123-154.

Nissim, D. (2003). Reliability of banks' fair value disclosure for loans. Review of Quantitative Finance and Accounting. 20 (1), 355-384.

Paulo, E. (2007). Manipulação das informações contábeis: uma análise teórica e empírica sobre os modelos operacionais de deteç̧ão de gerenciamento de resultados. Tese de doutorado, Programa de PósGraduação em Contabilidade, Universidade de São Paulo, São Paulo, Brasil. 260 p.

Quagli, A., \& Ricciardi, M. (2010, July). The IAS 39 October 2008 Amendment as another opportunity of earnings management: an analysis of the European banking industry. SSRN Working Paper. Recuperado em 9 dezembro, 2010,de http://papers.ssrn.com/sol3/ papers.cfm?abstract_id=1639925.

Ronen, J., \& Yaari, V. (2008). Earnings management. (v.3). Springer Series in Accounting Scholarship. New York: Springer.

Santos, E. C. (2007). Capital regulatório e gerenciamento de resultados nas instituições financeiras que atuam no Brasil. Dissertação de mestrado, Programa de Pós-Graduação em Ciências Contábeis, Fundação Instituto Capixaba de Pesquisas em Contabilidade, Economia e Finanças, Fucape, Vitória, Brasil, 129 p.

Shrieves, R. E., \& Dahl, D. (2003). Discretionary accounting and the behavior of japanese banks under financial duress. Journal of Banking and Finance. 27 (7), 1219-1243.

Xavier, P. H. M. (2007). Gerenciamento de resultados por bancos comerciais no Brasil. Tese de doutorado, Programa de Pós-Graduação em Contabilidade, Universidade de São Paulo, São Paulo. 139 p.

Zendersky, H. C. (2005). Gerenciamento de resultados em instituições financeiras no Brasil - 2000 a 2004. Dissertação de mestrado, Programa Multi-Institucional e Inter-Regional de Pós-Graduação em Ciências Contábeis, UnB, UFPB, UFRN, UFPE, Brasil.

\section{ANEXOS}

Tabela A.1 Testes Im, Pesaran e Shin (I.P.S.) de raízes unitárias das variáveis não dicotômicas dos modelos (3.1), (3.2) e (3.3).

\begin{tabular}{|c|c|c|c|c|c|c|c|c|c|c|c|c|}
\hline & RTVM & $T V M$ & $\Delta T V M$ & SEL & IBOV & $P I B$ & CAM & $T P F$ & ESTMN & $C D B L T$ & DEBAC & OUT \\
\hline Estatística I.P.S. & $-29,4496$ & $-11,4420$ & $-50,6553$ & $-7,2851$ & $-45,2970$ & $-27,1300$ & $-33,7978$ & $-2,4753$ & $-4,7675$ & $-739,3870$ & $-3,2666$ & $-10,9553$ \\
\hline p-valor & 0,0000 & 0,0000 & 0,0000 & 0,0000 & 0,0000 & 0,0000 & 0,0000 & 0,0067 & 0,0000 & 0,0000 & 0,0005 & 0,0000 \\
\hline & SVCT & AT12M & AT5A & AT15A & $S 15 A$ & $P U B$ & M10PR & M50PR & M100PR & DMPR & $\triangle A A P$ & $\ln A T$ \\
\hline Estatística I.P.S. & $-20,7373$ & $-11,1853$ & $-9,9223$ & $-101,9670$ & $-11,1333$ & $-7,5250$ & $-22,2764$ & $-8,5054$ & $-2,9461$ & $-7,4633$ & $-56,9885$ & $-7,1737$ \\
\hline p-valor & 0,0000 & 0,0000 & 0,0000 & 0,0000 & 0,0000 & 0,0000 & 0,0000 & 0,0000 & 0,0000 & 0,0000 & 0,0000 & 0,0000 \\
\hline
\end{tabular}

onde: RTVM é o resultado com títulos e valores mobiliários, escalonado pelos ativos totais do início do período; TVM o saldo da carteira de títulos e valores mobiliários, deflacionado pelos ativos totais do início do período; $\triangle T V M$ a variação na carteira de títulos e valores mobiliários, deflacionada pelos ativos totais do início do período; SEL a taxa básica de juros da economia, a Selic, anualizada; IBOV a variação do Ibovespa ; PIB a variação do Produto Interno Bruto a valores básicos; CAM a variação cambial real/dólar; TIP a proporção da carteira de TVM aplicada em cinco categorias de investimentos - títulos públicos federais (TPF), títulos públicos estaduais ou municipais (ESTMN), CDBs, letras imobiliárias e letras hipotecárias $(C D B L T)$, debêntures e ações $(D E B A C)$ e outros títulos $(O U T)$-; PRZ a proporção da carteira de TVM distribuída de acordo com o prazo de vencimento dos papéis - sem vencimento (SVCT), até 12 meses (AT12M), mais de 1 e até 5 anos $(A T 5 A)$, mais de 5 e até 15 anos $(A T 15 A)$ e superior a 15 anos (S15A) -; e CON o grau de concentração da carteira de TVM, identificando a proporção da carteira aplicada junto aos - emitentes públicos (PUB), 10 maiores emitentes privados (M1OPR), 50 seguintes maiores emitentes privados (M5OPR), 100 seguintes maiores emitentes privados (M100PR) e demais emitentes privados $(D M P R) ; \triangle A A P$ a variação na conta Ajuste de Avaliação Patrimonial, deflacionado pelos ativos totais do início do período; e InAT o logaritmo natural dos ativos totais. 


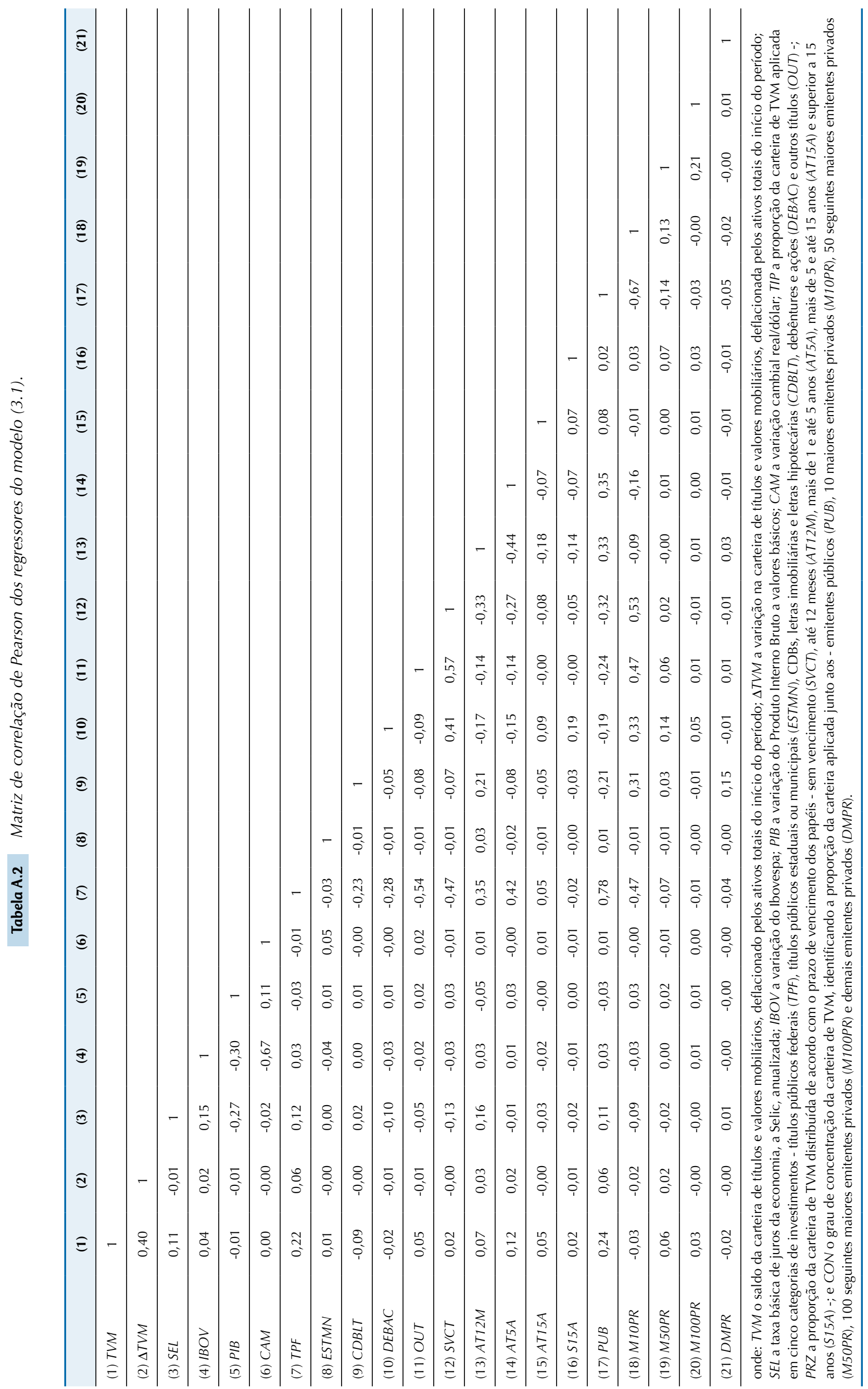


Tabela A.3 Matriz de correlação de Pearson dos regressores dos modelos (3.2) e (3.3).

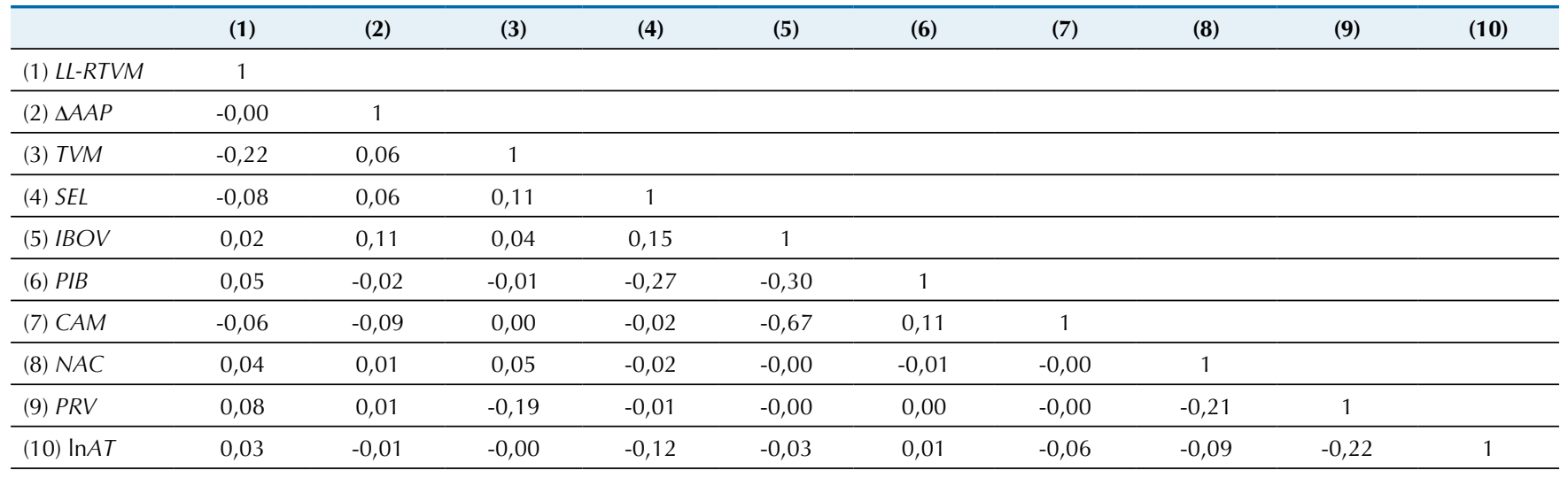

onde: RTVM é o resultado com títulos e valores mobiliários, deflacionado pelos ativos totais do início do período; $L L$ o lucro líquido, deflacionado pelos ativos totais do início do período; $\triangle A A P$ a variação na conta Ajuste de Avaliação Patrimonial, deflacionado pelos ativos totais do início do período; TVM o saldo da carteira de títulos e valores mobiliários, deflacionado pelos ativos totais do início do período; $S E L$ a taxa básica de juros da economia, a Selic, anualizada; IBOV a variação do Ibovespa; PIB a variação do Produto Interno Bruto a valores básicos; CAM a variação cambial real/dólar; NAC assume 1 para as instituições financeiras sob controle de capital nacional e 0 para as demais; $P R V$ assume 1 para as instituições financeiras de capital privado e 0 para as demais; e InAT o logaritmo natural dos ativos totais. 